\title{
Kabin kurutucuda kurutulan kuşburnu (Rosa canina L.) meyvesinin kuruma performansı, efektif difüzyon ve aktivasyon enerjisi değerlerinin belirlenmesi
}

\author{
Gazanfer ERGÜNEŞ ${ }^{1}$, Muhammed TAȘOVA ${ }^{1}$
}

${ }^{1}$ Gaziosmanpaşa Üniversitesi Ziraat Fakültesi Biyosistem Mühendisliği Bölümü, TOKAT

Alınıș tarihi: 24 Kasım 2017, Kabul tarihi: 05 Mart 2018

Sorumlu yazar: Muhammed TAŞOVA, e-posta:muhammed.tasova@gop.edu.tr

\section{$\ddot{0} \mathbf{z}$}

Türkiye 'de önemli bir üretim potansiyeline sahip olan kuşburnu meyvesi (Rosa canina L.) kurutularak alternatif şekillerde tüketilmektedir. $\mathrm{Bu}$ çalışmada kabin tip bir konvektif kurutucu kullanılarak 50, 60 ve $70^{\circ} \mathrm{C}$ kurutma havası sicaklıklarında kurutulmuştur. Ürün nemi yaş baza göre \% 10-15 seviyesine kadar kurutulan kuşburnu meyvesinin kuruma performansı, en uygun ince tabakalı matematiksel kuruma modeli, efektif difüzyon $\left(D_{\text {eff }}\right)$ ve aktivasyon enerji değerleri belirlenmiştir. Kurutma havası sıcaklık değerlerine göre belirlenen ortalama kuruma süreleri sırasıyla 16.5 , 7.5 ve 7 saat olarak belirlenmiştir. Kuşburnu meyvesinin ince tabakalı kuruma modellerini oluşturmak için literatürde yaygın olarak kullanılan Midilli-Küçük, Page ve Yağcıŏlu modelleri seçilmiştir. Oluşturulan kuruma modelleri içerisinde kuruma eğrilerini en iyi tahmin eden ince tabakalı matematiksel model Midilli-Küçük modeli olduğu belirlenmiştir. Kurutma işlemi esnasında belirlenen efektif difüzyon ( $D_{\text {eff }}$ ) değerleri $1.52 \times 10^{-5}-3.74 \times 10^{-5} \quad \mathrm{~m}^{2} / \mathrm{sn}$ aralığında değişirken aktivasyon enerji değeri ise $\left(E_{a}\right) 42.83$ $\mathrm{kj} / \mathrm{mol}$ olarak belirlenmiştir.

Anahtar kelimeler: Kuşburnu, kabin kurutucu, kuruma performansı, efektif difüzyon ve aktivasyon enerji değerleri
Determination of drying performance, effective diffusion and activation energy values for rosehip (Rosa canina L.) fruit dried with cabin dryer

\begin{abstract}
Rosehip fruit (Rosa canina L.), which has significant production potential in Turkey and in the world, is dried and consumed in alternative forms. In this study, the cabin was dried at a drying air temperature of 50,60 and $70{ }^{\circ} \mathrm{C}$ using a convective dryer. Drying performance of rosehip fruits dried to the extent of $10-15 \%$ according to the wet base of the product, optimal mathematical drying model with thin layer, effective diffusion $\left(D_{\text {eff }}\right)$ and activation energy values were determined. The average drying times determined for the product at the drying air temperatures of 50,60 and $70{ }^{\circ} \mathrm{C}$ were determined to be 16.5, 7.5 and 7 hours, respectively. Midilli-Küçük, Page and Yagcioglu mathematical models, widely used in the literature, have been chosen to form drying models of rosehip fruit. It is determined that the model with the smallest bedding is the Midilli-Küçük model. The effective diffusion $\left(D_{e f f}\right)$ values determined according to the drying temperatures were varied between $1.52 \times 10^{-5}$ $3.74 \times 10^{-5} \mathrm{~m}^{2} / \mathrm{sec}$ and the activation energy value $\left(E_{a}\right)$ was determined as $42.83 \mathrm{~kJ} / \mathrm{mol}$.

Key words: Rosehip, cabin dryer, drying performance, effective diffusion and activation energy values
\end{abstract}




\section{Giriş}

Kuşburnu meyvesi (Rosa canina L.) Türkiye'de olduğu gibi birçok Avrupa ülkesinde de yaygın bir şekilde yetişmektedir (Artik ve Eksi, 1988; Demir ve Özcan, 2001; Erentürk ve ark., 2005). Kuşburnu temelde C vitamini, potasyum ve fosfor gibi birçok besin elementi içermektedir. $100 \mathrm{~g}$ kuşburnu meyvesinde ortalama 300-4000 mg civarında C vitamini içerdiğ i bilinmektedir. $\mathrm{Bu}$ özelliği ile kuşburnu meyvesi tam bir C vitamini deposu özelliği tașımaktadır. Bununla beraber içerdiği diğer besin elementleri ise vücutta karaciğer, kalp, beyin ve endokrin bezlerinin sağlıklı bir șekilde çalışmasına katkı sağlamaktadır (Chrubasik ve ark., 2006; Leahu ve ark., 2014).

Kuşburnu yiyecek ve içecek olarak birçok şekilde tüketilmektedir. Kuşburnu meyvesi marmelat, şarap, reçel gibi gıda türlerinin yapımında direk kullanılmalarıyla beraber pasta, ekmek, çorba gibi gıdalarda ise katkı maddesi olarak kullanılmaktadır (Biçer ve Kar, 2013). Kuşburnu meyvesi taze ve kurutularak bir çok șekilde kullanımının yanında yaprak ve çiçek kısımları da kurutularak tüketilmektedir (Deliorman Orhan ve ark., 2007; Machmudah ve ark., 2008). Kurutulan kuşburnu meyveleri sıcak ve soğuk çay yapımında, çorbalarda ve dondurmalarda yaygın bir şekilde kullanılmaktadır (Barta, 2006; Mabellini ve ark., 2012). Kurutma; yaş meyvelerin uzun süre saklanması için tercih edilen en eski yöntemlerden biri olup, üründeki nemin büyük bir kısmının uzaklaştığı bununla beraber su aktivitesi değerinin düştüğü ve mikroorganizma faaliyetlerin çoğalmasının engellendiği bir gıda muhafaza yöntemidir (Pisalkar ve ark., 2011).

Tarımsal ürünlerin kurutulması için birçok yöntem kullanılmaktadır. Bunlardan biri de güneş enerjisinden yararlanılarak gerçekleştirilen doğal kurutma yöntemidir. Doğal kurutma yöntemi enerji tüketim değeri açısından uygun olması üreticiler tarafından en fazla tercih edilen yöntemdir. Ancak ürünler kurutulurken toz, toprak, kuş ve zararlı gazlardan korunamamakta ve kurutma havasının sıcaklığı kontrol edilemediğinden dolayı son kalite değeri açısından önemli sorunlar oluşturmaktadır. Bir çok üretici bu sebepten dolayı ürünlerinin kuruturken ısıtılmış hava ile çalışan konvektif kurutucuları tercih etmektedir (Doymaz ve ark., 2003; Özgen, 2014).

Kurutma çalışmalarında ürünün kuruma kinetiği hakkında bilgi edinmek için bazı parametreler kullanılmaktadır. $\mathrm{Bu}$ parametreler kurutma işlemlerini kontrol etmek, var olan kurutucuları geliştirmek, yeni bir kurutucu tasarlamak için veya üründen nemin uzaklaştırılması için gerekli enerji değerlerini bilmek için önemlidir.

Bu çalışmada kabin tip bir konvektif kurutucu ile kurutulan kuşburnu meyvesinin kuruma kinetiklerini belirlemek için, ürünün kuruma performansı, en uygun ince tabakalı matematiksel kurutma modeli, efektif difüzyon (Deff) ve aktivasyon enerji ( $\left.\mathrm{E}_{\mathrm{a}}\right)$ değerleri belirlenmiștir.

\section{Materyal Yöntem}

\section{Deneme mateyali}

Çalışmada kullanılan kuşburnu meyvesi Tokat Gaziosmanpaşa Üniversitesi bahçe bitkileri bölümü araştırma bahçesinden temin edilerek Biyosistem Mühendisliği Bölümü Kurutma Laboratuvarı'na getirilmiştir. Kurutma işlemleri sonlanana kadar ürünler $+4 \pm 0.5^{\circ} \mathrm{C}$ sicaklığa ayarlanan bir buz dolabında muhafaza edilmiștir.

\section{Nem tayini}

Taze kuşburnu meyvesinin nem içeriği 4 tekerrürlü ve her bir tekerrürde ortalama $25 \pm 0.2$ g örnek kullanılarak belirlenmiştir. Nem tayini işlemi $70{ }^{\circ} \mathrm{C}$ sıcaklığa ayarlanmış etüvde belirli aralıklarda ürünler dijital terazide (marka model, ülke) tartılarak ağırlık değişimi $0.01 \mathrm{~g}$ 'a düşüne kadar kurutulmuştur (Yağcioğlu, 1999). İlk ve son ağırlıkları bilinen kuşburnu meyvesinin ilk nem içeriği 1 ve 2 numarada verilen eşitlikler kullanılarak hesaplanmıştır.

$$
\begin{aligned}
& \mathrm{N}_{\mathrm{y}}=\frac{\mathrm{W}_{\mathrm{i}}-\mathrm{W}_{\mathrm{s}}}{\mathrm{W}_{\mathrm{i}}} \times 100 \\
& \mathrm{~N}_{\mathrm{k}}=\frac{\mathrm{W}_{\mathrm{i}}-\mathrm{W}_{\mathrm{s}}}{\mathrm{W}_{\mathrm{s}}} \times 100
\end{aligned}
$$

$\mathrm{N}_{\mathrm{y}}$ : Yaş baza göre nem (\%)

$\mathrm{N}_{\mathrm{k}}$ : Kuru baza göre nem (\%)

$W_{\mathrm{i}}$ : Ürün örneğinin ilk ağırlı̆̆ $(\mathrm{g})$

$\mathrm{W}_{\mathrm{s}}$ : Ürün örneğinin son ağırlı̆̆ı (g)

\section{Kurutma işlemi}

Kurutma işleminden önce materyal yıkanarak kötü olanlar ayıklanmış ve kurutma işlemi için eș görünümlü ürünler seçilmiştir. Daha sonra ürünler ikiye bölünerek çekirdekleri çıkartılmıştır. Kurutma işlemleri Şimşek Laborteknik marka ST - 055 ve ST 120 kabin tip iki kurutucular kullanılmıştır. Kurutma işlemleri 50,60 ve $70^{\circ} \mathrm{C}$ kurutma havası sıcaklıklarında $\quad 3^{\prime}$ er tekerrür halinde 
gerçekleştirilmiştir. Her tekerrürde ortalama $25 \pm 0.25 \mathrm{~g}$ ürün kullanılmıştır. Kurutma işlemleri esnasında 0.01 hassasiyete sahip terazi belirli süre aralıklarında tartılarak ürün nemi yaş baza göre \% 10-15 seviyesine kadar kurtulmuştur.

\section{Kurutucu}

Çalışmada Şimşek Laborteknik marka ST - 055 ve ST - 120 tip iki kabin kurutucular kullanılmıştır. ST 120 tip kurutucu ebat olarak diğerine göre büyük olup kurutma havası sıcaklığı $250^{\circ} \mathrm{C}$ sıcaklığa kadar ayarlanabilmektedir. ST - 055 tip kabin kurutucuda ise kurutma havası sıcaklığı $150^{\circ} \mathrm{C}$ sıcaklığa kadar ayarlanabilmektedir.

\section{Kuruma modeli}

Kurutulan kuşburnu meyvesinin zamana bağlı olarak ayrılan nem oranı değeri 3 numarada verilen eşitlik kullanılarak belirlenmiştir.

$$
\mathrm{ANO}=\frac{\mathrm{M}-\mathrm{M}_{\mathrm{e}}}{\mathrm{M}_{0}-\mathrm{M}_{\mathrm{e}}}
$$

ANO: Ayrılabilir nem oranı

\section{M: Kurutulan materyalin anlık nem içeriği}

$\mathrm{M}_{\mathrm{e}}$ : Kurutulan materyalin verilen durumdaki denge nemi

\section{$\mathrm{M}_{\mathrm{o}}$ : Kurutulan materyalin ilk nem içeriği}

Meyvenin kuruma eğrilerini oluşturmak için yaygın olarak kullanılan Midilli-Küçük, Page ve Yağcığlu ince tabakalı matematiksel kurutma modelleri seçilmiştir. Modellere ait eşitlikler Çizelge 1 . 'de verilmiştir.

Çizelge 1. İnce tabakalı matematiksel kurutma modelleri

\begin{tabular}{ccc}
\hline No & Model İsmi & Eşitlik \\
\hline 1 & Page & MR $=\exp (-\mathrm{h} \cdot(\mathrm{t}))$ \\
2 & Midilli küçük & MR = h.exp $\left(-\mathrm{j} \cdot\left(\mathrm{t}^{\mathrm{k}}\right)\right)+(\mathrm{l} \cdot \mathrm{t})$ \\
3 & Yağcloğlu & MR = k.exp(-h.t)+j \\
\hline
\end{tabular}

\section{Efektif difüzyon değerlerinin (Deff, $\mathrm{m}^{2} / \mathrm{s}$ ) belirlenmesi}

Üründen nemin uzaklaşması Fick yasasının ikinci kanunu olan süreye bağlı olarak uzaklaşan alan miktarı yani diğer bir ifade ile efektif difüzyon değeri hesaplanmıștır. Efektif difüzyon değeri belirlenirken ürünün doku yapısının korunduğu ve nemin sadece difüzyon yolu ile ortamdan uzaklaștığı varsayımı kabul edilerek 3 numaralı eşitlik kullanılarak belirlenmiştir (Crank, 1979).

$M R=\frac{M-M_{e}}{M_{0}-M_{e}}=\frac{8}{\pi} \sum_{n=0}^{\infty} \frac{1}{(2 n+1)^{2}} \exp \left[(2 n+1)^{2} \frac{\pi^{2}}{4} \frac{D_{\text {eff }} t}{L^{2}}\right]$
4 numaralı eşitlikte Deff efektif difüzyon değerini $\left(\mathrm{m}^{2} / \mathrm{sn}\right)$, L ürünün dilim kalınlığının (m) yarısını ifade etmektedir. Yaplan kurutma işlemlerinde difüzyon tek yönlü gerçekleşmiştir. 4 numaralı eşitlik matematiksel kurallara göre düzenlendikten 5 numaralı eşitlik elde edilmiştir.

In $M R=\operatorname{In} \frac{8}{\pi^{2}}-\frac{\pi^{2} D_{e f f} t}{4 L^{2}}$

Belirlenen boyutsuz nem oranı (MR) değerleri kuruma süresine göre bir doğru olușturulduğunda doğrunun eğiminden her kurutma şartı için ayrı $\mathrm{D}_{\text {eff }}$ değerleri hesaplanmıştır (Zakipour ve Hamidi, 2011).

Literatürde bazı ürünlerin kurutma şartları altında gösterdikleri efektif difüzyon değerleri belirlenmiştir. Bunlardan bazıları; Miranda ve ark. (2009) Aloe vera $\left(5.30-17.33 \times 10^{-10} \mathrm{~m}^{2} / \mathrm{sn}\right)$; Çelen ve ark. (2015) patates $\left(2.96 \times 10^{-7}-3.59 \times 10^{-6} \mathrm{~m}^{2} / \mathrm{s}\right)$; Sadi ve Meziane (2015) zeytin pirinası (3.55-20.47 $\times 10^{-9}$ $\mathrm{m}^{2}$ /sn); Kutlu ve İşçi (2016) patlıcan (1.75$21.66 \times 10^{-8} \mathrm{~m}^{2} / \mathrm{sn}$ ) ve Gür (2016) balkabağl (11.6$16.6 \times 10^{-10} \mathrm{~m}^{2} / \mathrm{s}$ ) gibi farklı ürünler üzerinde çalışmalar yapmışlardır.

\section{Aktivasyon enerji değerinin belirlenmesi}

Ürünün efektif difüzyon değerinin sıcaklığa bağlı değișimi Arrhenius eșitliği kullanılarak ifade edilmektedir (Karel ve Saguy, 1991).

$D_{\text {eff }}=D_{0} \exp \left(-\frac{E_{A}}{R T}\right)$

6 numaralı eşitliğe göre Do değeri difüzyon katsayısını $\left(\mathrm{m}^{2} / \mathrm{sn}\right), \mathrm{R}$ değeri gaz sabitini (8.3143 $\mathrm{kj} / \mathrm{mol} \mathrm{K}$ ), Ea aktivasyon enerji değerini ( $\mathrm{kj} / \mathrm{mol})$ ve $\mathrm{T}$ (Kelvin ${ }^{\circ}$ ) ise kurutma havası sıcaklığını ifade etmektedir. Aktivasyon enerji $\left(E_{a}\right)$ değeri efektif difüzyon (Deff) değerinin matematiksel olarak ln değeri hesaplandıktan sonra 1/T değerlerine karşılık bir doğru grafiği oluşturulmuştur. Elde edilen doğrunun eğim değerinden aktivasyon enerji değeri hesaplanmıştır (Türker ve İşleroğlu, 2017).

\section{Bulgular ve Tartışma}

\section{Kuruma verileri}

Kullanılan ürünün ortalama nem içeriği yaş baza göre \% 68.31 olarak belirlenmiştir. Yapılan kurutma ișlemlerinde ürünün nem içeriği yaș baza göre \% 1015 seviyesine kadar kurutulmuştur. Yıldız ve ark. (2015), muzun kuruma karakteristiğinin incelendiği çalışmada ürün neminin \% 10-15 seviyesine kadar kuruttuklarını ifade etmişlerdir. Kurutma şartları altında belirlenen ürüne ait ortalama kuruma 
performans değerleri, kuruma esnasındaki ağırlık değişimleri ve ürünün boyutsuz nem değerleri (MR) Çizelge 2, Şekil 1 ve 2'te verilmiştir. 50,60 ve $70{ }^{\circ} \mathrm{C}$ kurutma havası sıcaklıklarında kurutulan kuşburnu meyvesinin belirlenen ortalama kuruma süreleri sıcaklık değerlerine göre sırasıyla $16.5,7.5$ ve 7 saat olarak belirlenmiştir.
Çizelge 2. Kuşburnu meyvesinin kuruma performans değerleri

\begin{tabular}{ccc}
\hline $\begin{array}{c}\text { Sicaklık } \\
\text { Değerleri }\end{array}$ & $\begin{array}{c}\text { Ortalama Son } \\
\text { Nem Değerleri } \\
(\%)\end{array}$ & $\begin{array}{c}\text { Kuruma Süreleri } \\
\text { (Saat) }\end{array}$ \\
\hline $50^{\circ} \mathrm{C}$ & $\% 11,08$ & 16.5 \\
$60^{\circ} \mathrm{C}$ & $\% 10,33$ & 7.5 \\
$70^{\circ} \mathrm{C}$ & $\% 10,67$ & 7 \\
\hline
\end{tabular}

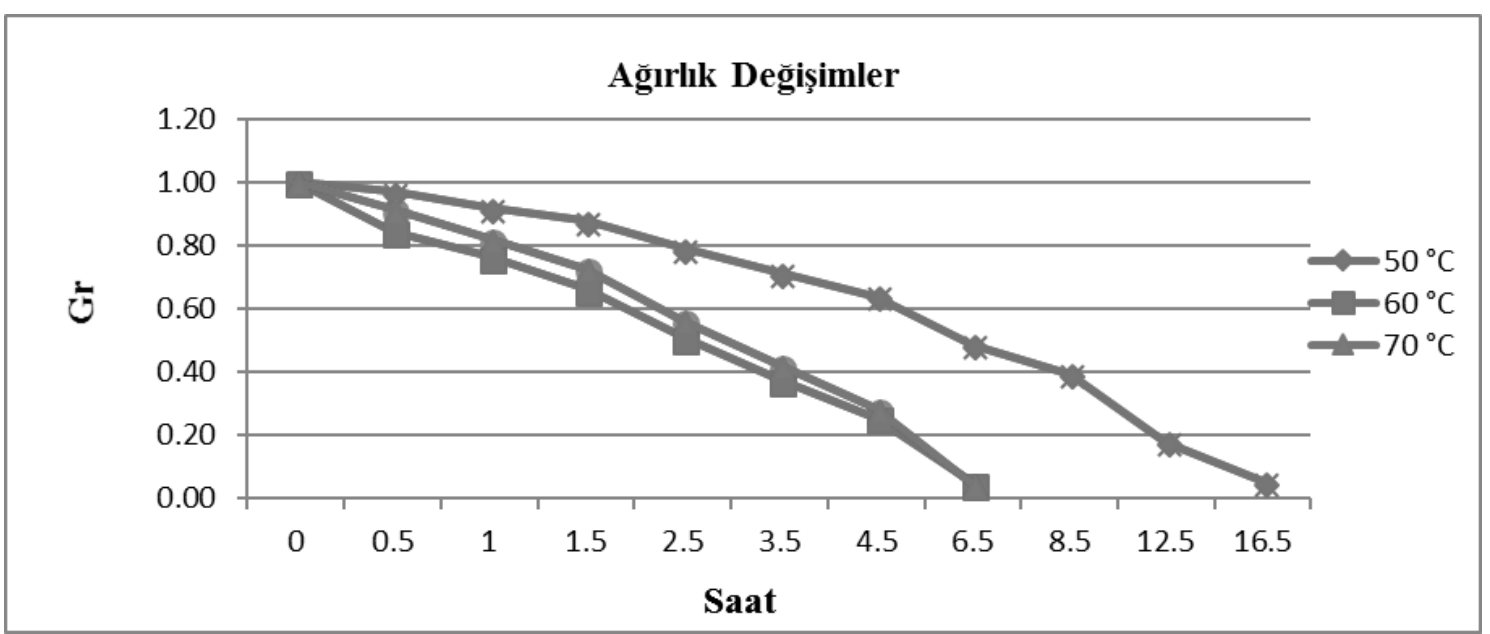

Şekil 1. Kuşburnu meyvesinin belirlenen ağırlık değișimleri

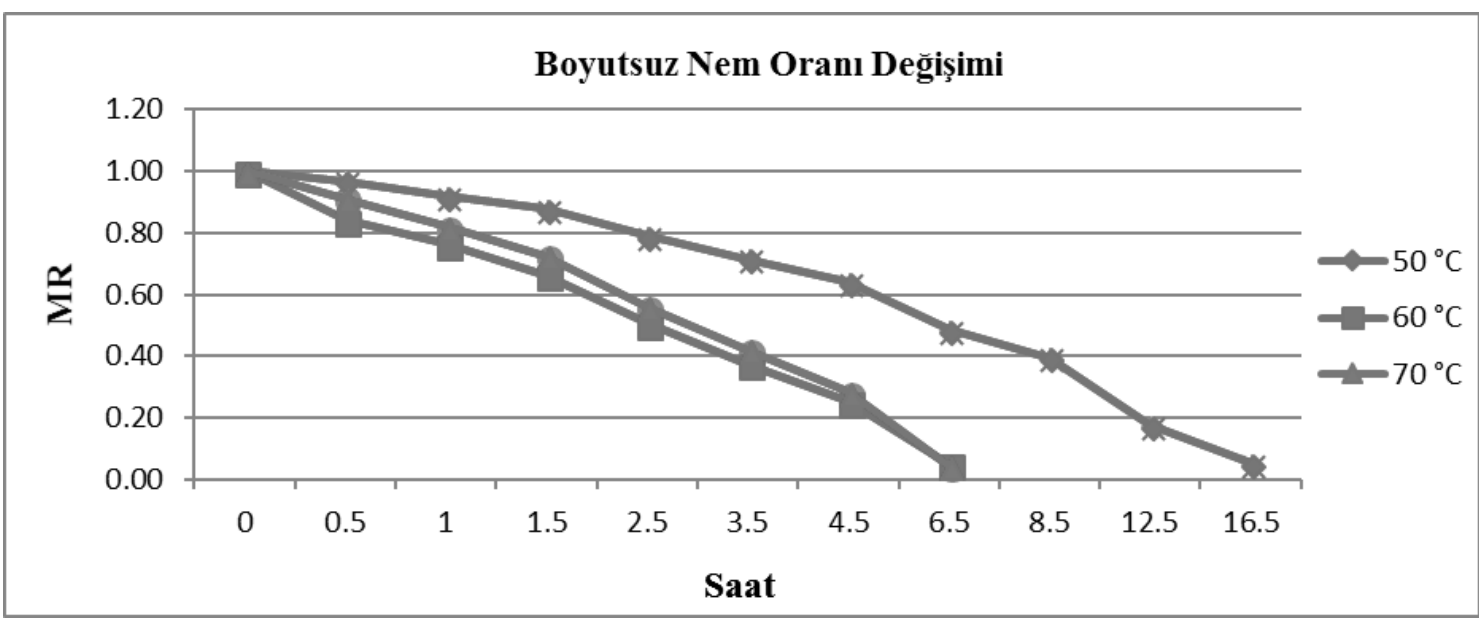

Şekil 2. Kuşburnu meyvesinin boyutsuz nem oranı (MR) değerlerinin değişimi

Uygulanan kurutma sıcaklığının ürünün kuruma performans değerlerini etkilediği ve sicaklık değerinin artmasıyla kuruma sürelerinin azaldığı belirlenmiștir. Kaya ve ark. (2015), trabzonhurmasının kurutulduğu çalışmada sıcaklığının artması ile ürünün kuruma oranının artığı ve kuruma süresinin azaldığını ifade etmişlerdir. Taşova (2016), sıcaklık kontrollü bir mikrodalga kurutucu ile yaptığı kurutma çalışmasında sıcaklığının artması ile ürünün kuruma süresinin azaldığını ifade etmiştir.

Kuruma modellerine ait katsayılar, " $R^{2}$ ve "p" değerleri

Kurutma işlemlerinde süreye bağlı ayrılabilir boyutsuz nem oranlarını belirlemek için kuruma eğrileri oluşturulmuştur. Kuruma modellerine ait katsayı ve $\mathrm{R}^{2}$ değerleri Çizelge 5 'te verilmiştir. 
Çizelge 5. İnce tabakalı matematiksel kurutma modellerinin katsayı ve $\mathrm{R}^{2}$ değerleri

\begin{tabular}{|c|c|c|c|c|}
\hline Model adı & Sicaklık $\left({ }^{\circ} \mathrm{C}\right)$ & Model sabitleri & $\mathrm{p}$ & $\mathrm{R}^{2}$ \\
\hline \multirow[b]{2}{*}{ Midilli-Küçük } & 50 & $\begin{array}{c}k=1,0962 \\
h=1,0031 \\
j=0,0761 \\
m=-0,0088\end{array}$ & \multirow[b]{2}{*}{$p<0.0001$} & 0.9994 \\
\hline & 60 & $\begin{array}{c}k=0,9307 \\
h=0,9964 \\
\mathrm{j}=0,2544 \\
\mathrm{~m}=-0,0194 \\
k=1,1011 \\
h=1,0015 \\
j=0,1689 \\
m=-0,0276\end{array}$ & & 0.9999 \\
\hline \multirow{3}{*}{ Page } & 50 & $\begin{array}{l}k=0,0681 \\
h=1,2692\end{array}$ & \multirow{3}{*}{$p<0.0001$} & 0.9963 \\
\hline & 60 & $\begin{array}{l}k=0,2646 \\
h=1,0929\end{array}$ & & 0.9939 \\
\hline & 70 & $\begin{array}{l}\mathrm{k}=0,1779 \\
h=1,3239\end{array}$ & & 0.9940 \\
\hline \multirow{3}{*}{ Yağcıoğlu } & 50 & $\begin{array}{l}k=1,4405 \\
h=0,0675 \\
j=-0,4286 \\
k=1,1737\end{array}$ & \multirow{3}{*}{$p<0.0001$} & 0.9993 \\
\hline & 60 & $\begin{array}{l}h=0,2142 \\
\mathrm{j}=-0,1872 \\
\mathrm{k}=1,6394\end{array}$ & & 0.9986 \\
\hline & 70 & $\begin{array}{l}h=0,1275 \\
j=-0,6301\end{array}$ & & 0.9997 \\
\hline
\end{tabular}

Midilli-Küçük modeli kuruma eğrilerini en iyi $70^{\circ} \mathrm{C}$ kurutma havası sıcaklı̆̆ında tahmin etmiştir. Modelin güvenilirlik değeri tüm kurutma şartları için ( $\mathrm{p}<0,05)$ uygun bulunmuştur. Midilli-Küçük modeline ait en büyük "k" değeri $70^{\circ} \mathrm{C}$ kurutma havası sıcaklığında belirlenirken en küçük "k" değeri

$60^{\circ} \mathrm{C}$ kurutma havası sıcaklığında belirlenmiștir. Modele ait en büyük "h" değeri $50^{\circ} \mathrm{C}$ kurutma havası sıcaklığında belirlenirken en küçük " $h$ " değer ise $60^{\circ} \mathrm{C}$ kurutma havası sıcaklığında belirlenmiştir. En büyük "j" değeri $60^{\circ} \mathrm{C}$ kurutma havası sıcaklığında elde edilirken en küçük "j" değeri $50^{\circ} \mathrm{C}$ kurutma havası sıcaklığında elde edilmiştir. Modele ait en büyük "m" değeri ise $50^{\circ} \mathrm{C}$ kurutma havası sıcaklığında belirlenirken en küçük "m" değeri $70^{\circ} \mathrm{C}$ kurutma havası sıcaklığında belirlenmiștir.

Page modeli kuruma eğrilerini en iyi $50^{\circ} \mathrm{C}$ kurutma havası sıcaklığında tahmin etmiştir. Modelin güvenilirlik değeri tüm kurutma şartları için uygun $(p<0,05)$ bulunmuştur. Page modeline ait en büyük "k" değeri $60^{\circ} \mathrm{C}$ kurutma havası sıcaklığında belirlenirken en küçük "k" değeri ise $50^{\circ} \mathrm{C}$ kurutma havası sıcaklığında belirlenmiştir. Modele ait en büyük "h" değeri ise $70^{\circ} \mathrm{C}$ kurutma havası sıcaklığında elde edilirken en küçük "h" değeri $60{ }^{\circ} \mathrm{C}$ kurutma havası sıcaklığında elde edilmiștir.
Yağcıŏlu modeli kuruma eğrilerini en iyi $70^{\circ} \mathrm{C}$ kurutma havası sıcaklığında tahmin etmiştir. Modelin güvenilirlik değeri tüm kurutma sıcaklığ için $(p<0,05)$ uygun bulunmuştur. Yağcioğlu modeline ait en büyük "k" değeri $70{ }^{\circ} \mathrm{C}$ kurutma havası sıcaklığında belirlenirken en küçük "k" değeri $60^{\circ} \mathrm{C}$ kurutma havası sıcaklığında belirlenmiştir. Modele ait en büyük " $\mathrm{h}$ " değeri $60^{\circ} \mathrm{C}$ kurutma havası sıcaklığında belirlenirken en küçük "h" değeri $50{ }^{\circ} \mathrm{C}$ kurutma havası sıcaklığında belirlenmiştir. En büyük "j" değeri ise $60^{\circ} \mathrm{C}$ kurutma havası sıcaklığında belirlenirken en küçük "j" değeri $70^{\circ} \mathrm{C}$ kurutma havası sıcaklığında belirlenmiştir.

Uygulanan tüm kurutma havası sıcaklıklarında $\mathrm{R}^{2}$ değeri en yüksek olan yani kuruma eğrilerini en iyi tahmin eden ince tabakalı matematiksel kurutma modelinin Midilli-Küçük modeli olduğu belirlenmiştir.

\section{Efektif difüzyon (Deff) değerleri}

Uygulanan kurutma şartları altında hesaplanan ürünün efektif difüzyon değerleri Çizelge 3 'te verilmiştir.

Çizelgeye göre kurutma sıcaklığının efektif difüzyon değerini etkilediği ve kurutma sıcaklığının artmasıyla efektif difüzyon değerinin arttığ belirlenmiştir. $50,60,70^{\circ} \mathrm{C}$ kurutma havası 
sıcaklıklarında kurutulan kuşburnu meyvesinin sıcaklık değerlerine göre sırasıyla $1.52 \times 10^{-5}$, $3.63 \times 10^{-5}$ ve $3.74 \times 10^{-5}$ olarak belirlenmiştir. Belirlenen efektif difüzyon katsayısının süreye bağlı LN (MR) değerinin değişimi Şekil 3 'te verilmiştir.
Çizelge 3. Kuşburnu meyvesinin belirlenen efektif difüzyon değerleri

\begin{tabular}{cc}
\hline Kurutma Sıcaklıkları & $\begin{array}{c}\text { Efektif Difüzyon (D eff) Değerleri } \\
\left(\mathrm{m}^{2} / \mathrm{sn}\right)\end{array}$ \\
\hline $50^{\circ} \mathrm{C}$ & $1.52 \times 10^{-5}$ \\
$60^{\circ} \mathrm{C}$ & $3.63 \times 10^{-5}$ \\
$70^{\circ} \mathrm{C}$ & $3.74 \times 10^{-5}$ \\
\hline
\end{tabular}

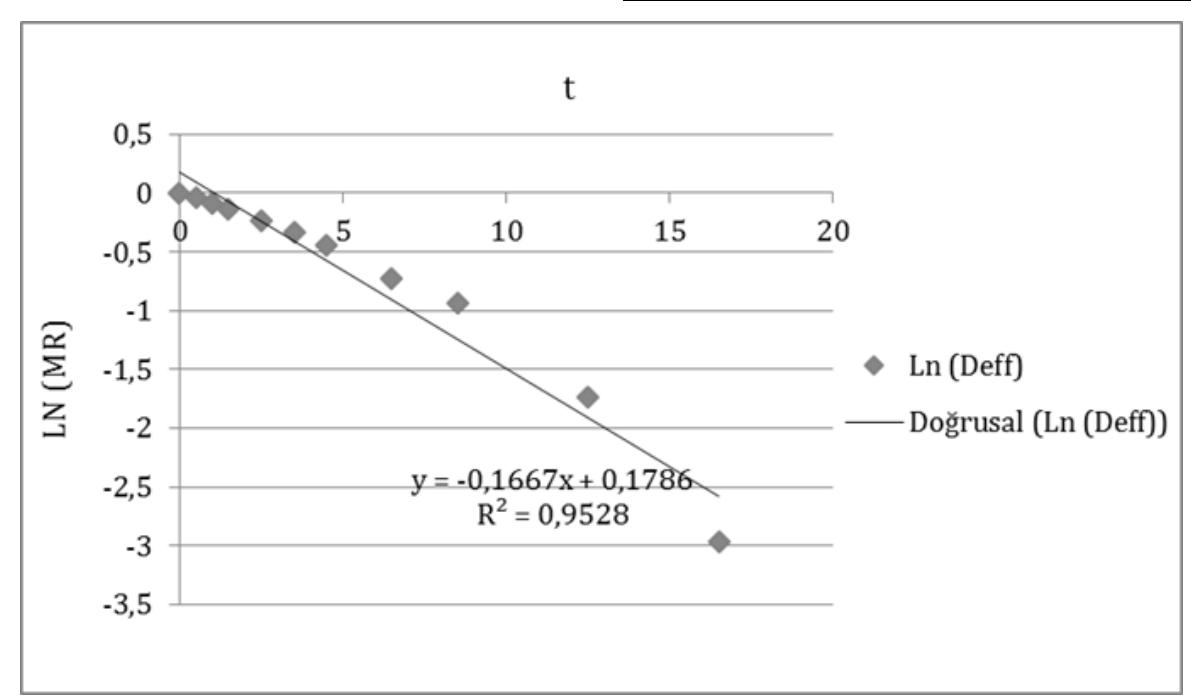

Şekil 3. Süreye bağlı LN (MR) değerinin en yüksek R² değerine sahip efektif difüzyon katsayı eğrisi

Literatürde; Meisami-asl ve ark. (2010), beş farklı $\left(40,50,60,70\right.$ ve $\left.80^{\circ} \mathrm{C}\right)$ kurutma sicaklı̆̆ında kurutulan elmanın kurutma havası sıcaklığı ürünün efektif difüzyon değerini etkilediği ve sıcaklık değerinin artması ile efektif difüzyon değerinin arttığı ve en yüksek efektif difüzyon değerini ise $80^{\circ} \mathrm{C}$ kurutma sicaklığında belirlediklerini ifade etmişlerdir. Parlak, (2014), üç farklı kurutma sıcaklığında $\left(40,50\right.$ ve $\left.60^{\circ} \mathrm{C}\right)$ kurutulan zencefilin efektif difüzyon değeri uygulanan kurutma sıcaklık değerleri tarafından etkilendiği ve en yüksek efektif difüzyon değerini ise $60^{\circ} \mathrm{C}$ kurutma havası sıcaklığında belirlediğini ifade etmiștir. Demiray ve Tülek (2016), üç farklı $\left(25,35,45^{\circ} \mathrm{C}\right)$ kurutma sıcaklıklarında kurutulan bamyanın efektif difüzyon değeri sıcaklık değerleri tarafından etkilendiği ve en yüksek efektif difüzyon değerinin ise $45^{\circ} \mathrm{C}$ kurutma sıcaklığında belirlediklerini ifade etmişlerdir. Türker ve İşleroğlu (2017), beş farklı (50, 60,70, 80 ve $\left.90^{\circ} \mathrm{C}\right)$ kurutma sıcaklığında kurutulan kuşburnu pulpunun efektif difüzyon değeri sıcaklık değerleri tarafından etkilendiği ve sıcaklık değerinin artmasıyla efektif difüzyon değerinin arttığını ifade etmişlerdir.

\section{Aktivasyon enerjisi ( $\left.E_{a}\right)$ değeri}

Çalışma kurutma şartları altında belirlenen kuşburnu meyvesinden aktivasyon enerji değerinin
$42.83 \mathrm{kj} / \mathrm{mol}$ olduğu belirlenmiştir. Literatürde konvektif kurutucu ile kurutulan bazı ürünlerin aktivasyon enerjisi değerlerini; Aghbashlo ve ark. (2009) patates için $39.49 \mathrm{kj} / \mathrm{mol}$; Doymaz (2012) hurma için $43.26 \mathrm{kj} / \mathrm{mol}$; Vega-Galvez ve ark. (2012) altın çilek için $38.78 \mathrm{kj} / \mathrm{mol}$; Demiray ve Tülek, (2014) sarımsak için $30.58 \mathrm{kj} / \mathrm{mol}$; Zhu ve Shen (2014) şeftali için $42.23 \mathrm{kj} / \mathrm{mol}$ olarak tespit etmişlerdir.

\section{Sonuç}

Kuşburnu meyvesi içerdiği besin değerleri ve etken maddeleri açısından hem besleyici hem de birçok hastalığın tedavisinde iyileştirici etkisinin olduğu bilinmektedir. $\mathrm{Bu}$ nedenle kuşburnu meyvesini mevsimi dışında da bozulmadan uzun süre saklanabilmesi için kurutulması gerekmektedir.

Çalışmada kabin tip bir konvektif kurutucu ile 50, 60 ve $70^{\circ} \mathrm{C}$ kurutma havası sicaklıklarında kurutulan kuşburnunun kuruma performansı, en uygun ince tabakalı matematiksel kuruma modeli, efektif difüzyon ve aktivasyon enerji değerleri belirlenmiştir. Çalışmada belirlenen en uzun kuruma süresi 16.5 saat ile $50^{\circ} \mathrm{C}$ kurutma havası sıcaklığında belirlenirken en kısa kuruma ise 7 saat ile $70^{\circ} \mathrm{C}$ kurutma havası sıcaklığında belirlenmiștir. 
Kurutulan kuşburnu meyvesinin oluşturulan kuruma eğrileri içerisinde en iyi tahmin eden ince tabakalı matematiksel kurutma modelinin Midilli-Küçük modeli olduğu belirlenmiștir. Kurutma havası sıcaklık değerleri kuşburnunun efektif difüzyon değerlerini etkilediği ve belirlenen Deff değerlerinin ise $\quad 1.52 \times 10^{-5}-3.74 \times 10^{-5}$ arasında değiştiği belirlenmiştir. Üründen bir mol su uzaklaştırmak için gerekli aktivasyon enerji değerinin ise 42.83 $\mathrm{kj} / \mathrm{mol}$ olduğu belirlenmiştir.

\section{Kaynaklar}

Aghbashlo, M., Kianmehr M.H, Arabhosseini, A.. 2009. Modeling of thin-layer drying of potato slices in length of continuous band dryer. Energy Conver Manag, 50, 1348-1355.

Artik, N., Eksi, A., 1988. Studies on chemical composition of some wild fruits (Rosa canina, Crataegus monogyna, Crataegus aronia, Vaccinium myriltlus and Berberries vulgaris). Food Industry, 9, 33-34.

Barta, J., 2006. Handbook of fruit and fruit 542 proccesing. In Y. Hui (Ed.), (First Edi- 543 tion, Chap. Fruit Drying Principles). Ox- 544 ford, Blackwell Publishing.

Bicer, A., Kar. F., 2013. Experimental Investigation of Drying Behavior of Rosehip in a Cyclone-Type Dryer. Engineering and Technology International Journal of Nutrition and Food Engineering, Vol:7, No:6.

Chrubasik, C., Duke, R.K., Chrubasik, S., 2006. The evidence for clinical efficacy of rose Hip and seed: a systematic review, Phytotherapy Research: An International Journal Devoted to Pharmacological and Toxicological Evaluation of Natural Product Derivatives, 20(1): 1-3.

Crank, J., 1979. The mathematics of diffusion. Oxford universitypress, London.

Çelen, İ.H., Çelen, S., Moralar, A., Buluş, H.N., Önler, E., 2015. Mikrodalga Bantlı Kurutucuda Patatesin Kurutulabilirliğinin Deneysel Olarak İncelenmesi. Electronic Journal of Vocational Colleges, Özel Sayı, 57-69.

Demir, F., Ozcan, M., 2001. Chemical and technological properties of rose (Rosa canina L ) fruits grown wild in Turkey. Research note. Journal of Food Engineering, 47, 333-336.

Demiray, E., Tülek, Y., 2014. Drying characteristics of garlic (Allium sativum L) slices in a convective hot air dryer. Heat and Mass Trans, 50, 779-786.

Demiray, E., Tülek, Y., 2016. Günește Kurutulmuş Bamyaların Rehidrasyon Kinetiği. Akademik Gida 14 (4), 368-374.
Doymaz, İ., 2012. Evaluation of some thin-layer drying models of persimmon slices (Diospyros kaki L.). Energy Conver Manag, 56, 199-205.

Doymaz, İ., Tuğrul, N., Pala, M. 2003. "Maydanozun Kuruma Karakteristiklerinin İncelenmesi," Yıldız Teknik Üniversitesi Dergisi, 3: 1-8.

Erenturk, S., Gulaboglu, M.S., Gultekin, S., 2005. The effects of cutting and drying medium on the vitamin $\mathrm{C}$ content of rosehip during drying. J Food Eng, 68 (4): 513-518.

Gür, M., 2016. Balkabağının Akışkan Yataklı Kurutucuda Kurutulmasının Deneysel Ve Teorik İncelenmesi. Uludağ Üniversitesi Mühendislik Fakültesi Dergisi, $21,2$.

Karel M., Saguy I., 1991. Effects of water on diffusion in foodsystems. in: Water Relationships in Foods. Editor Harry Levine and Louise Slade. Publ. by Springer Science Business Media. 157-173.

Kaya, A., Kamer, M.S., Şahin, H.E., 2015. Trabzon Hurmasının (Diospyros kaki L.) Kuruma Davranışının Deneysel İncelenmesi. Gıda 40 (1): 15-21. doi: 10.15237/gida.GD14047.

Kutlu, N., İșci, A., 2016. Farklı Kurutma Yöntemlerinin Patlıcanın Kurutma Karakteristikleri Üzerine Etkisi ve Kurutmanın Matematiksel Modellenmesi. Akademik Gıda 14 (1), 21-27.

Leahu, A., Damian, C., Oroian, M., Ropciuc, S. and Rotaru, R., 2014. Influence of Processing on Vitamin C Content of Rosehip Fruits. Animal Science and Biotechnologies, 47 (1).

Mabellini, A., Ohaco, E., Marquez, C.A., Michelis, A.D., Lozano, J.E., 2012. Effects of pretreatments on convective drying of rosehip (Rosaeglanteria). International Journal of Food Studies, 1, 42-51.

Machmudah, S., 2008. Process optimization and extraction rate analysis of carotenoids extraction from rosehip fruit using supercritical CO $2 \mathrm{~J}$. of Supercritical Fluids, 44:308-314.

Meisami-asl, E.,Rafiee, S., Keyhani, A., Tabatabaeefar, A., 2010. Determination of suitable thin layer drying curve model for apple slices (variety-Golab). Plant Omics Journal, 3 (3):103-108.

Miranda, M., Maureira, H., Rodriguez, K., Vega-Galvez, A. (2009), Influence of temperature on the drying kinetics, physicochemical properties, and antioxidant capacity of Aloe Vera (Aloe Barbadensis Miller) gel, Journal of Food Engineering, 91, 297-304.

Deliorman Orhan, D.., Hartevioglu, A., Kupeli, E. Yesilada, E., 2007. In vivo anti-inflammatory and antinociceptive activity of the crude extract and 
fractions from Rosa canina L. Fruits. Journal of Ethnopharmacology, 112: 4-400.

Özgen, F., 2014. Elma Kurutulmasında Kullanılan Konvektif Tip Bir Kurutma Sisteminin Tasarımı. Mühendis ve Makine, 55, 656, 42-49.

Parlak, N., 2014. Akışkan Yataklı Kurutucuda Zencefilin Kuruma Kinetiğinin İncelenmesi. Gazi Üniversitesi Mühendislik Mimarlık Fakülte Dergisi, 29 (2), 261269.

Pisalkar, P. S., Jain, N. K., Jain, S. K., 2011. Osmo-air drying of aloe vera gel cubes. Journal of food science and technology-mysore 48-2, 183-189.

Sadi, T., Meziane, S., 2015. Mathematical modelling, moisture diffusion and specific energy consumption of thin layer microwave drying of olive pomace. International Food Research Journal 22 (2): 494-501.

Taşova, M., 2016. Sıcaklık Kontrollü Bir Mikrodalga Kurutucu Geliştirilmesi Ve Performansının Belirlenmesi. Yüksek Lisans Tezi, Gaziosmanpaşa Üniversitesi, Tokat.
Türker, İ., İşleroğlui H., 2017. Mahlep Püresinin Kızılötesi Işınım İle Kurutulması İşleminde Antosiyanin, Fenolik Madde Ve Antioksidan Kapasite Değişim Kinetiği. Gıda Dergisi, 42 (4), 422-430.

Vega-Galvez, A., Miranda, M., Diaz, L.P., Lopez, L., Rodriguez, K., Di-Scala, K.. 2010. Effective moisture diffusivity determination and mathematical modelling of the drying curves of the olive-waste cake. Bioresour Technol, 101, 7265-7270.

Yağcıoglu, A., 1999. Tarımsal Ürünleri Kurutma Tekniği. Ege Üniversitesi ziraat fakültesi yayınları No: 536 . Bornova, İzmir.

Yıldız, A.K., Polatci, H., Uçun, H., 2015. Farklı Kurutma Şartlarında Muz (Musa cavendishii) Meyvesinin Kurutulması ve Kurutma Kinetiğinin Yapay Sinir Ağları ile Modellenmesi. Tarım Makineleri Bilimi Dergisi 11 (2), 173-178.

Zhu, A., Shen, X., 2014. The model and mass transfer characteristics of convection drying of peach slices. Int J Heat and Mass Trans, 72, 345-351. 